\title{
Direct comparison of 3D and 2D cultivation reveals higher osteogenic capacity of elderly osteoblasts in 3D
}

Stephan Payr ${ }^{1,2^{*}}$ (D), Elizabeth Rosado-Balmayor ${ }^{1,3}$, Thomas Tiefenboeck $^{2}$, Tim Schuseil ${ }^{1}$, Marina Unger ${ }^{1}$, Claudine Seeliger ${ }^{1}$ and Martijn van Griensven ${ }^{1,4}$

\begin{abstract}
Background: The aim of this study was the investigation of the osteogenic potential of human osteoblasts of advanced donor age in 2D and 3D culture.

Methods: Osteoblasts were induced to osteogenic differentiation and cultivated, using the same polystyrene material in 2D and 3D culture for 2 weeks. Samples were taken to evaluate alkaline phosphatase (ALP) activity, mineralization and gene expression.

Results: Osteoprotegerin (OPG) levels were significantly increased (8.2-fold) on day 7 in 3D compared to day 0 ( $p<$ $0.0001)$ and 11.6-fold higher in 3D than in 2D $(p<0.0001)$. Both culture systems showed reduced osteocalcin (OC) levels (2D 85\% and 3D 50\% of basic value). Collagen type 1 (Col1) expression was elevated in 3D on day 7 (1.4-fold; $p=0.009$ ). Osteopontin (OP) expression showed 6.5-fold higher levels on day $7(p=0.002)$ in 3D than in 2D.

Mineralization was significantly higher in 3D on day 14 ( $p=0.0002)$.

Conclusion: Advanced donor age human primary osteoblasts reveal significantly higher gene expression levels of $\mathrm{OPG}$, Col1 and OP in 3D than in monolayer. Therefore, it seems that a relatively high potential of bone formation in a natural 3D arrangement is presumably still present in osteoblasts of elderly people.
\end{abstract}

Trial registration: 5217/11 on the 22nd of Dec. 2011.

Keywords: Donor age, Osteoblasts, 2D/3D cultivation

\section{Introduction}

Trauma of the elderly is a rising issue in trauma and orthopaedic surgery. Fracture healing itself is a complex physiologic process in which numerous cytokines, angiogenic factors, proteases and morphogens with significant roles are involved [1, 2]. Despite intensive research, many regulation mechanisms involved in bone healing

\footnotetext{
* Correspondence: stephan.payr@meduniwien.ac.at

'Department of Experimental Trauma Surgery, Klinikum Rechts der Isar, Technical University Munich, Munich, Germany

${ }^{2}$ Department of Orthopedics and Trauma Surgery, Division of Trauma

Surgery, Medical University of Vienna, Waehringer Guertel 18-20, 1090 Vienna, Austria

Full list of author information is available at the end of the article
}

are still not clear [3]. One cell type in the centre of attention are the osteoblasts, which are fibroblast-like cells derived from pluripotent mesenchymal stem cells (MSCs) [4]. Osteoblasts are bone-forming cells and express typical osteoblastic markers such as collagen type 1 (Col1), osteocalcin (OC), alkaline phosphatase (ALP) and osteoprotegerin (OPG) [5-7]. These osteoblastic markers indicate osteoblast's activity and represent bone formation, except for OPG, which is a glycoprotein produced by osteoblasts suppressing bone resorption and increases bone mass [8].

Human aging is associated with bone loss leading to bone fragility and increased risk of fractures and

C C The Author(s). 2021 Open Access This article is licensed under a Creative Commons Attribution 4.0 International License, which permits use, sharing, adaptation, distribution and reproduction in any medium or format, as long as you give appropriate credit to the original author(s) and the source, provide a link to the Creative Commons licence, and indicate if changes were made. The images or other third party material in this article are included in the article's Creative Commons licence, unless indicated otherwise in a credit line to the material. If material is not included in the article's Creative Commons licence and your intended use is not permitted by statutory regulation or exceeds the permitted use, you will need to obtain permission directly from the copyright holder. To view a copy of this licence, visit http://creativecommons.org/licenses/by/4.0/ The Creative Commons Public Domain Dedication waiver (http://creativecommons.org/publicdomain/zero/1.0/) applies to the data made available in this article, unless otherwise stated in a credit line to the data. 
morbidity in the geriatric population leading to a decline in the quality of life for the elderly as well as a substantial burden on the health care system [9]. Age-related osteoblast dysfunction is the main cause of age-related bone loss in both men and women beyond the fifth decade [10]. In general terms, age-related bone loss is characterized by reduced bone formation due to decreased number of osteoblasts and lowered activity. A further cellular mechanism for bone loss is an impairment of the osteogenic potential because of decreased MSCs leading to reduced expression of osteoblastic markers $[10,11]$. Age-related osteoblast dysfunction is also associated with impaired proliferation, a decline in functional lifespan and a decrease in differentiation, function and activity [10]. These age-related changes are caused by extrinsic mechanisms mediated by hormones and growth factors and intrinsic mechanisms caused by osteoblastic cell senescence [12]. New approaches to avoid cell senescence are the addition of growth factors and the usage of three-dimensional cultivation [13, 14]. Several growth factors that enhance osteoblast activity and consequently bone formation include insulin-like growth factors (IGFs) $[15,16]$, bone morphogenetic proteins (BMPs) [17] and prostaglandins [18]. Using a 3D cultivation system is supposed to mimic physiological conditions and provide a more accurate in vitro representation of in vivo conditions for cells undergoing osteogenic differentiation compared to monolayer cultivation resulting in different cell-cell contact and interaction between cells [19]. Although studies using monolayer culture are easy and good, 3D culture systems are necessary to reproduce in vivo conditions and to mimic the complexity of tissue. 3D cultures have a high biological relevance for 3D tissues and are important for better understanding of human tissue physiology. In the literature, 3D cultivation leads to improved proliferation and differentiation in cell culture [14, 19-21].

The aim of this study was the investigation of the osteogenic potential of primary human osteoblasts of advanced age in $2 \mathrm{D}$ compared to $3 \mathrm{D}$ cultivation systems to identify mechanisms for impaired fracture healing in elderly patients in further studies. This insight might be important to prevent and manage healing complications in the elderly in the future.

\section{Methods}

\section{Cell isolation and cultivation}

Human primary osteoblasts were isolated from femoral heads of 6 female patients (age $75.25 \pm 7.6$ ) scheduled to undergo hip replacement surgery. Informed consent was obtained from all participants. The study was conducted according to the Declaration of Helsinki in its latest amendment. Cells were isolated and cultured in monolayer according to our standard operation procedure, as previously described [22]. Briefly, the cancellous bone was extracted and washed three times. The bone fragments were placed in flasks and osteogenic culture medium-10\% fetal calf serum (Sigma-Aldrich, Munich, Germany), 1\% penicillin/streptomycin (PAA, Pasching, Austria), $50 \mu \mathrm{g} / \mathrm{ml} \mathrm{L-Ascorbat-2-Phophat} \mathrm{(Sigma-Aldrich,}$ Munich, Germany) in Dulbecco's modified Eagle's medium (DMEM) low glucose (Sigma-Aldrich, Munich Germany)-was added. The bone fragments were incubated for 7 days at $37^{\circ} \mathrm{C}$. Then, the medium was changed and the cells were again incubated for one more week. From then on, the medium was changed twice a week. Bone fragments were removed and osteoblasts were proliferated in monolayer culture in T75 culture flasks until passage 3 and then brought into 2D or 3D culture. For monolayer cultivation, $1 \times 10^{4}$ cells $/ \mathrm{cm}^{2}$ were seeded in 24-well plates. Cells were cultured in osteogenic culture medium-5\% FCS (Sigma-Aldrich, Munich, Germany), $1 \%$ pen/strep (PAA, Pasching, Austria), $10 \mathrm{mM} \beta$ glycerolphosphate (Sigma-Aldrich, Munich, Germany), $1.56 \mathrm{mM} \mathrm{CaCl} 2$ (Sigma-Aldrich, Munich, Germany), 100 nM dexamethasone (Sigma-Aldrich, Munich, Germany), 0.025 M HEPES (PAA, Pasching, Austria), $0.2 \mathrm{mM} \mathrm{L-as-}$ corbic-2-phosphat (Sigma-Aldrich, Munich, Germany) in DMEM low glucose (Sigma-Aldrich, Munich, Germany). A $200-\mu \mathrm{m}$-thick polystyrene scaffold (Alvatex Scaffolds, Reinnervate, Sedgefield, England) was used as a scaffold $(\varnothing 22 \mathrm{~mm})$ for 3D culture. The scaffold characteristics are $13 \mu \mathrm{m}$ thin linings and lacunae with a mean diameter of $40 \mu \mathrm{m}$. Osteoblasts were seeded at $1.5 \times 10^{6}$ cells per scaffold after the scaffolds were rinsed with $70 \%$ ethanol and washed with culture medium. Scaffolds with seeded cells were incubated for $2 \mathrm{~h}$. After incubation, scaffolds were put in 6-well plates with $8 \mathrm{ml}$ culture medium as described above. Medium was changed every second day. For evaluating 3D culture, scaffolds were divided to obtain samples for each investigation. For evaluating 2D culture, cells were pooled from two wells out of a 24-well plate for each investigation. Samples were collected on days 0, 3, 7 and 14 to perform analysis of alkaline phosphatase (ALP) activity, alizarin red staining (mineralization), sulforhodamine $B$ determination (SRB) and gene expression with reverse transcriptase PCR (RT-qPCR).

\section{Alkaline phosphatase activity}

Cells and scaffold samples at the abovementioned times were transferred in alkaline phosphate substrate solution containing of $3.5 \mathrm{mM}$ 4-nitrophenyl-phosphate-di-sodium-hexahydrit salt (Sigma-Aldrich) in a $0.1 \mathrm{mM}$ ALP buffer (50 mM glycine, $100 \mathrm{mM}$ tris-base, $2 \mathrm{mM} \mathrm{MgCl}_{2}$, $\mathrm{pH} 10.5$ - Sigma-Aldrich) and incubated at $37^{\circ} \mathrm{C}$ for 30 min. As negative control, ALP substrate solution without cells was used. Absorbance was measured at $405 \mathrm{~nm}$, and p-nitrophenol concentrations were calculated 
according to standard curve and divided through the protein content calculated with SRB determination [23].

\begin{abstract}
Alizarin red staining (mineralization)
Alizarin red staining and measurement were performed to measure mineralization. Cultured cells were fixed with ice-cold ethanol $96 \%$ for $30 \mathrm{~min}$ in a 24 -well plate. After washing twice with $\mathrm{dH}_{2} \mathrm{O}, 400 \mu \mathrm{l}$ alizarin red staining solution was added in each well for $10 \mathrm{~min}$, washed again four times. The stain was eluted for 20 min into a solution of $10 \%$ hexadecylpyridiniumchloride (SigmaAldrich). Absorbance was read at $562 \mathrm{~nm}$. Alizarin red concentration for samples was calculated according to standard curve and results were normalized to the protein content analysed via SRB staining [23].
\end{abstract}

\section{Sulforhodamine B determination (SRB)}

As mentioned above SRB staining was performed to normalize alizarin red staining and ALP activity. Cells were fixed with methanol for $15 \mathrm{~min}$ at room temperature after culture medium was removed and cells washed with DPBS. Next, the SRB staining solution was added and incubated for $30 \mathrm{~min}$ at room temperature on a shaker. After removing SRB staining solution and washing the plates with $1 \%$ acetic acid solution followed by $10 \mathrm{mM}$ unbuffered TRIS solution, cells were incubated again at room temperature on the shaker for $15 \mathrm{~min}$. Absorbance was read at 565 and $690 \mathrm{~nm}$. Total protein in osteoblasts was calculated using the following equation: Total protein $[\mu \mathrm{g} / \mu \mathrm{l}]=(\mathrm{OD}-0.036) / 0.036[24]$.

\section{Total RNA isolation and reverse transcriptase-polymerase} chain reaction

Cell-scaffold composites and cells in 2D of each group were taken and lysed using TRIzol reagent (SigmaAldrich, Munich, Germany) according to our standard operation procedure $[25,26]$. The purity and concentration of total RNA was determined by spectrophotometry (Biophotometer + HELLMA tray cell, Eppendorf, Hamburg, Germany). cDNA synthesis [27] was performed using first-strand cDNA synthesis kit (Fermentas, St. Leon-Rot, Germany) according to manufacturer's instruction. Reverse transcriptase polymerase chain reaction (RT-PCR) amplification was performed and monitored using a Master Cycler S (Eppendorf, Hamburg, Germany).

The thermal cycling conditions comprised the initial steps at $98^{\circ} \mathrm{C}$ for $3 \mathrm{~min}$. The amplification step of the cDNA products was performed with 40 PCR cycles, consisting of a denaturation step at $98^{\circ} \mathrm{C}$ for $10 \mathrm{~s}$ and an annealing step at a variable temperature depending on the primer for $10 \mathrm{~s}$. As internal control, $\beta$-tubulin was chosen as the housekeeping gene. All cDNA samples (30 ng of cDNA) were analysed in duplicates. Quantitative polymerase chain reaction (q-PCR) amplification was performed and monitored using a Q-PCR CFX96 (BioRad, California, USA). Relative quantification of gene expression was performed using the comparative $\Delta \Delta \mathrm{Ct}$ method. The following genes were used for analysis: alkaline phosphatase (ALP), osteoprotegerin (OPG), osteocalcin (OC), osteopontin (OP) and collagen type $1 \alpha 1$ (Col1). Amplification primers are listed in Table 1. Gene expression data were reported as the mean \pm standard deviation of the realtime PCR analyses. For statistical analysis $\Delta \Delta \mathrm{Ct}$ values were used.

\section{Statistical analysis}

Results were calculated with GraphPad Prism 6. Samples are not normally distributed; therefore, a non-parametric one-way ANOVA test was performed followed by Tukey's multiple comparison test. Statistical significance was set for $p<0.05$.

\section{Results}

\section{Alkaline phosphatase activity}

In both cultivation systems, an increase of ALP activity levels was present on day 7 (2D: 1.9-fold, 3D: 3.3-fold) compared to day 0 (Fig. 1). The ALP activity levels were followed by a reduction on day 14 in both cultivation systems compared to day 7 . The kinetic course is similar in both groups but with higher levels by trend in the 3D culture.

\section{Alizarin red staining (mineralization)}

On day 7 , similar increased levels could be observed in both groups compared to day 0 (2D over 100-fold; $p<$ 0.0001) (Fig. 1). A distinct reduction of mineralization was following on day 14 in 2D culture compared to day 7. In the 3D group, a continuous increase was present until day 14 with significant higher levels (6.6-fold) compared to the basic value on day $0(p=0.0013)$. Comparing the two culture systems after 14 days, 8.4-fold higher levels were detected in the $3 \mathrm{D}$ group $(p=0.0002)$.

\section{Gene expression Alkaline phosphatase (ALP)}

In the 2D group, a 3.7-fold increase was observed on day 7 compared to day 0 , but no statistical difference was present (Fig. 2). At similar basic values, a 4.7 -fold gain on day 7 compared to day 0 was demonstrated in the 3D group after a constant increase over the observation period.

\section{Osteoprotegerin (OPG)}

The 2D group showed a slight reduction of expression levels on day 7 compared to day 0 (Fig. 2). At equal basic levels, the 3D group demonstrated a significant 8.2-fold increase of OPG expression comparing day 0 with day 7 $(p<0.0001)$; day 0 with day 3 ( 1.9 -fold; $p=0.0398)$; and 
Table 1 Human primers used for the quantitative PCR evaluation

\begin{tabular}{|c|c|c|c|}
\hline Gene & Forward primer $5^{\prime} \rightarrow 3^{\prime}$ & Reverse primer $5^{\prime} \rightarrow 3^{\prime}$ & Accession number \\
\hline OC & CCAGCGGTGCAGAGTCCAGC & GACACCCTAGACCGGGCCGT & NM-199173.3 \\
\hline OP & CTCCATTGACTCGAACGACTC & CGTCTGTAGCATCAGGGTACTG & NM-000582 \\
\hline ALP & CTGGGCTCCAGGGATAAAGC & TCAGTGTCTCTTGCGCTTGG & NM-000478.4 \\
\hline OPG & CCGGAAACAGTGAATCAACTC & AGGTTAGCATGTCCAATGTG & NM-002546.3 \\
\hline COL1 & AGCGGACGCTAACCCCCTCC & CAGACGGGACAGCACTCGCC & NM-000088.3 \\
\hline$\beta$-Tub & GAGGGCGAGGACGAGGCTTA & TCTAACAGAGGCAAAACTGAGCACC & NM-001069.2 \\
\hline
\end{tabular}

OC osteocalcin, OP osteopontin, ALP alkaline phosphatase, OPG osteoprotegerin, Col1 collagen type 1a1, $\beta$-Tub $\beta$-tubulin

day 3 with day 7 (4.25-fold, $p<0.0001)$ of the 3D culture. Comparing the two cultivation systems, an 11.6-fold increase of OPG levels was present in the 3D group after the observation period of 7 days $(p<0.0001)$.

\section{Osteocalcin (OC)}

Both groups demonstrated a reduction of OC levels after 7 days compared to day 0 (Fig. 2). In 3D culture, a distinct initial decrease was observed on day 3 compared to day 0 . Followed by an increase up to $50 \%$ of the basic value of day 0 on day 7 . After 7 days, slightly elevated OC levels (85\% of the basic value of day 0 ) compared to the $3 \mathrm{D}$ group were found in the $2 \mathrm{D}$ group.

\section{Collagen type 1 a1 (Col1)}

Both groups again revealed similar basic values at day 0 (Fig. 2). The 2D osteoblasts showed a steady expression rate of Col1 on day 7. After a significant decline in the $3 \mathrm{D}$ group on day $3(p=0.0004)$ compared to day 0 , a 1.4-fold increase above the basic value (day 0 ) was observed on day $7(p=0.009)$. From day 3 to day 7 , a 4fold rise was present in the 3D group $(p<0.0001)$. Comparing the two cultivation systems, 1.4-fold higher Col1 levels were seen in the 3D group at the end of the observation period $(p=0.0077)$.

\section{Osteopontin (OP)}

The initial high levels of OP in the 2D culture showed a significant reduction on day 7 compared to day $0(p<$ 0.0001 ) (Fig. 2). In the 3D group, there was also a significant reduction of $60 \%$ on day 3 ( $p=0.0001)$ compared to day 0 , followed by a slight increase up to $50 \%$ of the basic value of day 0 . On day 7 , it still represented a significant reduction compared to the levels on day 0 ( $p=$ 0.0015). Comparing the two cultivation systems, 6.5 -fold higher levels of OP were present in the 3D group after 7 days of observation $(p=0.0002)$.

\section{Discussion}

The data in this study indicates that elderly primary human osteoblasts achieve higher osteogenic levels in 3D than in monolayer culture. Coll was significantly higher in the 3D culture. Coll is expressed in the early phase of proliferation and indicates an early stage of maturation. This protein is also the most abundant compound in the extracellular matrix (ECM) of bone [28]. The expression

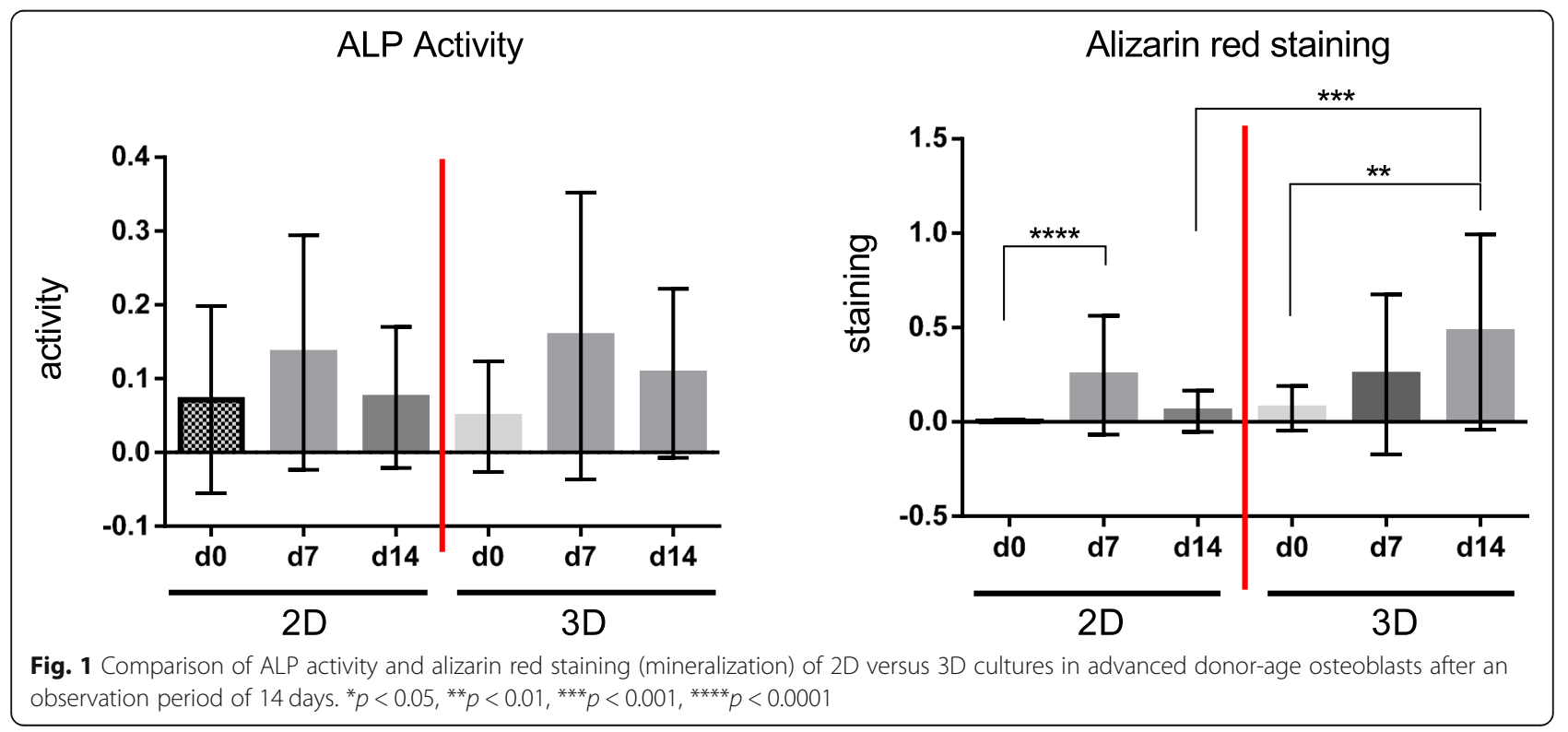



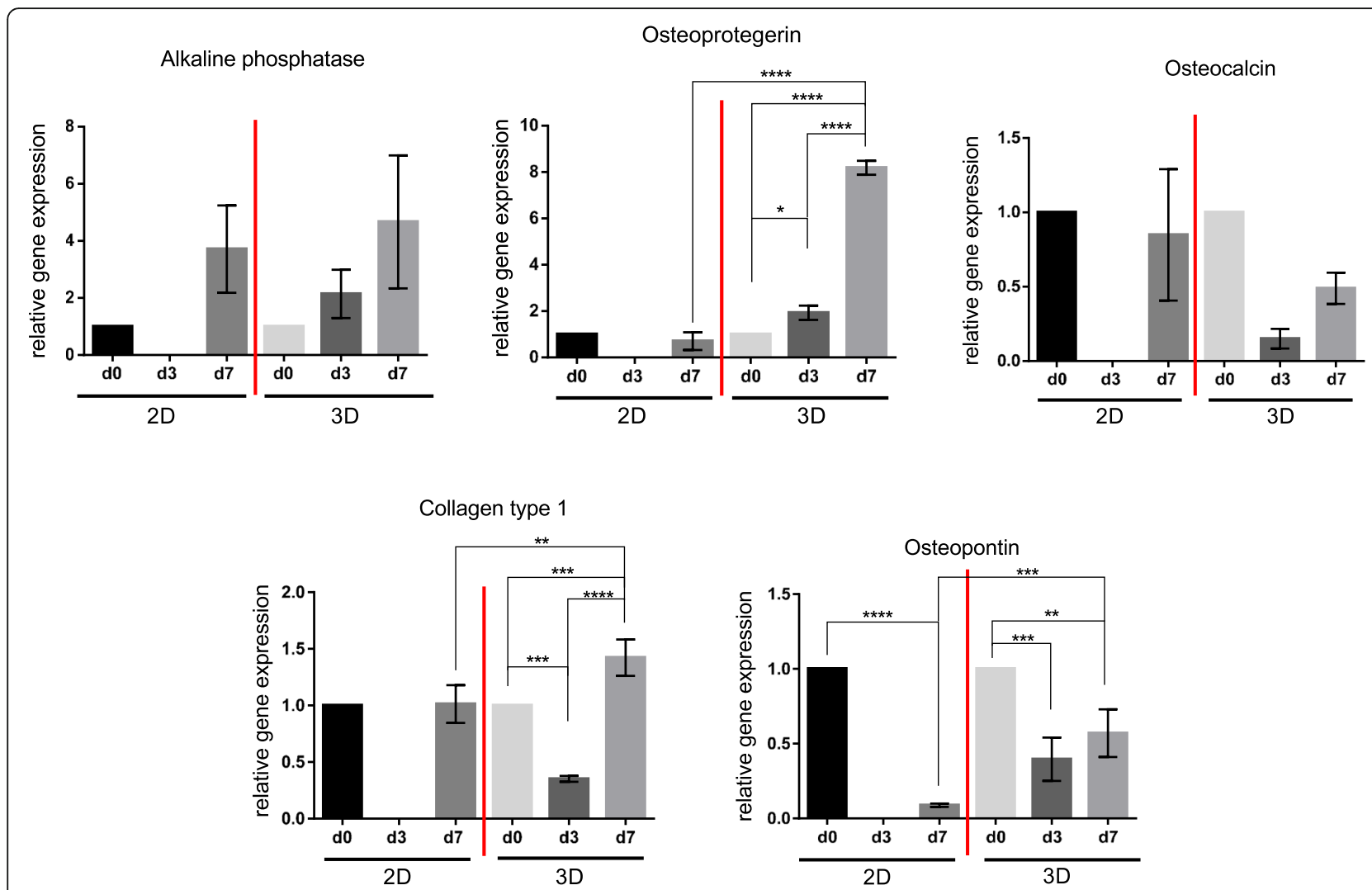

Fig. 2 Relative gene expression of ALP, OPG, OC, Col1 and OP. Comparison of $2 \mathrm{D}$ versus $3 \mathrm{D}$ cultures in advanced donor-age osteoblasts after an observation period of 14 days. ${ }^{*} p<0.05,{ }^{* *} p<0.01$, ${ }^{* *} p<0.001$, ${ }^{* * *} p<0.0001$

of OP and OC are indicators of maturation of ECM [28]. OP levels were significantly higher in $3 \mathrm{D}$ culture after the observation time. By trend, levels of $\mathrm{OC}$ were slightly lower than in monolayer culture. Alizarin red staining was significantly higher in the 3D cultivated cells representing the mineralization of ECM. The expression of OPG was also significantly elevated in 3D culture. An explanation for these significantly elevated gene expressions of osteogenic markers of elderly primary human osteoblasts in 3D culture might be that osteoblasts are primarily used to a $3 \mathrm{D}$ environment. In vivo osteoblasts are primarily positioned in a $3 \mathrm{D}$ arrangement. Due to cell isolation via out-migrating in monolayer culture, cells are not able to maintain mature phenotype [29]. After cultivation in monolayer, culture cells were rearranged in a 3D structure mimicking in vivo conditions. This consideration is supported by elevation of early markers (Col1), maturation makers (OP) and mineralization evidence (alizarin red staining), representing improved results during the whole osteogenic process.

Interesting is also the comparison of this present data of old osteoblasts in 3D culture to data of a previous conducted study of ours on old adipose derived mesenchymal stem cells (adMSCs) in 3D culture [30]. The previous study followed the same experimental setup including the same 3D cultivation systems and materials, concentration of osteogenic medium, investigations and observation period with the same time-points as in this present study. The comparison revealed an elevation of early osteogenic markers in osteoblasts. Levels of Col1 were significantly higher $(p<0.0001)$ and ALP was by trend higher in osteoblasts in 3D compared to elderly adMSCs in 3D. OPG levels are also significantly elevated in osteoblasts compared to adMSCs $(p<0.0001)$.

$\mathrm{OP}$, an early marker, signalling the end of proliferation and the beginning of ECM deposition did not show a significant difference comparing the OP expression of elderly osteoblasts and elderly adMSCs in 3D culture. OC, being a late marker of osteoblast maturation in the mineralization phase, did not reveal a significant difference between elderly osteoblasts and elderly adMSCs in $3 \mathrm{D}$ culture as well. The alizarin red staining illustrating mineralized ECM was by trend higher in elderly osteoblasts compared to elderly adMSCs in 3D culture. This comparison of data demonstrated elevated early osteogenic markers (Col1, ALP) in 3D osteoblasts. In contrast to adMSCs, osteoblasts might have an advantage, because they do not have to undergo the whole process of differentiation. Furthermore, due to the presence of a 
3D environment prior to isolation, osteoblasts are supposedly used to the 3D arrangement. Therefore, this cell type might readjust faster to the $3 \mathrm{D}$ environment and resume its function. The fact that $\mathrm{OC}$, as a late osteoblast marker and OP as a further maturation marker, exhibited low levels in both groups might be explained that both cell types were not fully (re-) differentiated yet. However, elderly osteoblasts seem to return faster to their original function than eldery adMSCs, due to the higher expression of early osteogenic markers. Concluding from this data adMSCs should be differentiated into osteoblasts in vitro before being brought in vivo for therapeutic use to achieve higher quality of bone formation.

This study is one of few directly comparing $2 \mathrm{D}$ and $3 \mathrm{D}$ culture systems [30-32]. A variety of 3D cultivation systems (bioreactors, scaffolds, additives and compounds) makes it difficult to obtain direct comparisons. In this study, the same culture material (polystyrene) without any additives was used for both culture systems. A further positive aspect is that this study is based on a model using primary osteoblasts. A popular choice for osteoblast culture studies are immortalized cell lines, which have the advantage of defined characteristics and a known differentiation state [29, 33, 34]. Still, immortalized cells cannot truly recapitulate the phenotype of a primary osteoblast, and because of this, it is favourable to have a model based on primary osteoblasts as in this present study [29]. A limitation of this study would be missing complete physiological conditions in vivo, which can only be mimicked with a $3 \mathrm{D}$ arrangement in vitro.

Summarizing, elderly human primary osteoblasts reveal significantly higher gene expression levels of OPG, Col1 and OP in 3D culture than in 2D culture. Therefore, a relatively high potential of bone formation in a natural 3D arrangement is presumably still present in osteoblasts of advanced donor age (elderly people). Osteoblasts may not be used for therapeutic intention, but this insight is important for physiological understanding. Autologous bone transplantation is in fact the transplantation of osteoblasts in a natural matrix. Therefore, in elderly trauma patients, additional osteogenic measures may be needed. The identification of the mechanisms leading to impaired fracture healing in patients with increased age is of significant importance in order to allow prevention and better management of these healing complications in the elderly.

The clinical relevance of these findings indicate a valid consideration to use osteoblasts of advanced donor age for bone tissue engineering purposes to treat bone defects or mal/non-unions in elderly patients like some other well-established procedures for other tissues like autologous chondrocyte implantation. For basic research, a combination of such osteoblasts of advanced donor age and mesenchymal stem cells in co-culture experiments with a longer observational period would be of interest to evaluate the impact of these findings for bone tissue engineering purposes.

\section{Abbreviations}

2D: Two-dimensional; 3D: Three-dimensional; adMSC: Adipose-derived mesenchymal stem cell; ALP: Alkaline phosphatase; BMP: Bone morphogenetic protein; Col1: Collagen type 1a1; ECM: Extracellular matrix; IGF: Insulin-like growth factor; MSC: Mesenchymal stem cell; OC: Osteocalcin; OP: Osteopontin; OPG: Osteoprotegerin; PCR: Polymerase chain reaction; SRB: Sulforhodamine B

\section{Acknowledgements}

The authors would like to thank Ellen Payr, PhD, and Fritz Seidl, M.A., for interpreting, translating, proofreading and linguistically editing this manuscript.

\section{Authors' contributions}

ERB and MvG designed the study. TS, CS and MU conducted the experiments. SP, TS, TT, ERB and MvG did the data analysis. SP, TT and ERB wrote the manuscript. All authors revised the manuscript and gave their final consent. The author(s) read and approved the final manuscript.

\section{Funding}

No funding was received fort his study.

\section{Availability of data and materials}

The datasets used and/or analysed during the current study are available from the corresponding author on reasonable request.

\section{Ethics approval and consent to participate}

The study was approved by the Institutional Review Board of the Technical University Munich (5217/11).

\section{Consent for publication}

Not applicable.

\section{Competing interests}

The authors declare that they have no competing interests.

\section{Author details}

'Department of Experimental Trauma Surgery, Klinikum Rechts der Isar, Technical University Munich, Munich, Germany. ${ }^{2}$ Department of Orthopedics and Trauma Surgery, Division of Trauma Surgery, Medical University of Vienna, Waehringer Guertel 18-20, 1090 Vienna, Austria. ${ }^{3}$ Department IBE, MERLN Institute, Maastricht University, Universiteitssingel 40, 6229 ER Maastricht, The Netherlands. ${ }^{4}$ Department CBITE, MERLN Institute, Maastricht University, Universiteitssingel 40, 6229 ER Maastricht, The Netherlands.

Received: 16 November 2020 Accepted: 9 December 2020

Published online: 06 January 2021

References

1. Einhorn TA. The cell and molecular biology of fracture healing. Clin Orthop Relat Res. 1998;(355 Suppl):S7-21.

2. Gerstenfeld $L C$, et al. Fracture healing as a post-natal developmental process: molecular, spatial, and temporal aspects of its regulation. J Cell Biochem. 2003;88(5):873-84.

3. Joyce ME, et al. Transforming growth factor-beta and the initiation of chondrogenesis and osteogenesis in the rat femur. J Cell Biol. 1990;1 10(6): 2195-207.

4. Aubin JE. Advances in the osteoblast lineage. Biochem Cell Biol. 1998;76(6): 899-910.

5. Eghbali-Fatourechi GZ, et al. Circulating osteoblast-lineage cells in humans. N Engl J Med. 2005;352(19):1959-66.

6. Eghbali-Fatourechi GZ, et al. Characterization of circulating osteoblast lineage cells in humans. Bone. 2007;40(5):1370-7. 
7. Kottstorfer J, et al. Are OPG and RANKL involved in human fracture healing? J Orthop Res. 2014;32(12):1557-61.

8. Schneeweis LA, Willard D, Milla ME. Functional dissection of osteoprotegerin and its interaction with receptor activator of NF-kappaB ligand. J Biol Chem. 2005;280(50):41155-64.

9. Syed FA, Melim T. Rodent models of aging bone: an update. Curr Osteoporos Rep. 2011;9(4):219-28.

10. Kassem M, Marie PJ. Senescence-associated intrinsic mechanisms of osteoblast dysfunctions. Aging Cell. 2011;10(2):191-7.

11. Pignolo RJ, et al. Defects in telomere maintenance molecules impair osteoblast differentiation and promote osteoporosis. Aging Cell. 2008;7(1): 23-31.

12. Marie PJ, Kassem M. Osteoblasts in osteoporosis: past, emerging, and future anabolic targets. Eur J Endocrinol. 2011;165(1):1-10.

13. Luu HH, et al. Distinct roles of bone morphogenetic proteins in osteogenic differentiation of mesenchymal stem cells. J Orthop Res. 2007;25(5):665-77.

14. Diederichs $\mathrm{S}$, et al. Application of different strain regimes in twodimensional and three-dimensional adipose tissue-derived stem cell cultures induces osteogenesis: implications for bone tissue engineering. J Biomed Mater Res A. 2010;94(3):927-36.

15. Hock JM, Centrella M, Canalis E. Insulin-like growth factor I has independent effects on bone matrix formation and cell replication. Endocrinology. 1988; 122(1):254-60.

16. Baylink DJ, Finkelman RD, Mohan S. Growth factors to stimulate bone formation. J Bone Miner Res. 1993:8(Suppl 2):S565-72.

17. Knutsen $R$, et al. Regulation of insulin-like growth factor system components by osteogenic protein-1 in human bone cells. Endocrinology. 1995;136(3):857-65.

18. Keila S, Kelner A, Weinreb M. Systemic prostaglandin E2 increases cancellous bone formation and mass in aging rats and stimulates their bone marrow osteogenic capacity in vivo and in vitro. J Endocrinol. 2001;168(1):131-9.

19. Gabbay JS, et al. Osteogenic potentiation of human adipose-derived stem cells in a 3-dimensional matrix. Ann Plast Surg. 2006;57(1):89-93.

20. Suck K, et al. A rotating bed system bioreactor enables cultivation of primary osteoblasts on well-characterized Sponceram regarding structural and flow properties. Biotechnol Prog. 2010;26(3):671-8.

21. van Griensven $M$, et al. Mechanical strain using $2 \mathrm{D}$ and $3 \mathrm{D}$ bioreactors induces osteogenesis: implications for bone tissue engineering. Adv Biochem Eng Biotechnol. 2009;112:95-123.

22. Dillon JP, et al. Primary human osteoblast cultures. Methods Mol Biol. 2012; 816:3-18.

23. Stanford CM, et al. Rapidly forming apatitic mineral in an osteoblastic cell line (UMR 106-01 BSP). J Biol Chem. 1995;270(16):9420-8.

24. Voigt W. Sulforhodamine B assay and chemosensitivity. Methods Mol Med. 2005;110:39-48

25. Chomczynski P, Sacchi N. The single-step method of RNA isolation by acid guanidinium thiocyanate-phenol-chloroform extraction: twenty-something years on. Nat Protoc. 2006;1(2):581-5.

26. Chomczynski P. A reagent for the single-step simultaneous isolation of RNA, DNA and proteins from cell and tissue samples. Biotechniques. 1993;15(3): 532-4 536-7.

27. Wiame I, et al. Irreversible heat inactivation of DNase I without RNA degradation. Biotechniques. 2000;29(2):252-4 256.

28. Lian JB, Stein GS. Concepts of osteoblast growth and differentiation: basis for modulation of bone cell development and tissue formation. Crit Rev Oral Biol Med. 1992;3(3):269-305.

29. Jahn K, et al. Pellet culture model for human primary osteoblasts. Eur Cell Mater. 2010;20:149-61.

30. Payr S, et al. Effect of donor age and 3D-cultivation on osteogenic differentiation capacity of adipose-derived mesenchymal stem cells. Sci Rep. 2020;10(1):10408.

31. Lin L, Chow KL, Leng Y. Study of hydroxyapatite osteoinductivity with an osteogenic differentiation of mesenchymal stem cells. J Biomed Mater Res A. 2009;89(2):326-35.

32. Danoux CB, et al. In vitro and in vivo bioactivity assessment of a polylactic acid/hydroxyapatite composite for bone regeneration. Biomatter. 2014;4: e27664
33. Kartsogiannis $\mathrm{V}, \mathrm{Ng} \mathrm{KW}$. Cell lines and primary cell cultures in the study of bone cell biology. Mol Cell Endocrinol. 2004;228(1-2):79-102.

34. Pautke $C$, et al. Characterization of osteosarcoma cell lines MG-63, Saos-2 and U-2 OS in comparison to human osteoblasts. Anticancer Res. 2004; 24(6):3743-8.

\section{Publisher's Note}

Springer Nature remains neutral with regard to jurisdictional claims in published maps and institutional affiliations.
Ready to submit your research? Choose BMC and benefit from:

- fast, convenient online submission

- thorough peer review by experienced researchers in your field

- rapid publication on acceptance

- support for research data, including large and complex data types

- gold Open Access which fosters wider collaboration and increased citations

- maximum visibility for your research: over $100 \mathrm{M}$ website views per year

At BMC, research is always in progress.

Learn more biomedcentral.com/submissions 